\title{
El Régimen Jurídico del Patrimonio de la Seguridad Social transferido a la Comunidad Autónoma de Andalucía
}

\author{
Antonio Alfonso García García \\ Letrado de Administración Sanitaria \\ Servicio Andaluz de Salud
}

\begin{abstract}
SUMARIO: $1^{\circ}$ Régimen Jurídico del Patrimonio de la Seguridad Social.- $2^{\text {o }}$ Régimen Jurídico de los bienes inmuebles de la Seguridad Social transferidos a la Comunidad Autónoma de Andalucía. Traspasos en materia sanitaria.- $3^{\circ}$ Referencia a los bienes inmuebles traspasados en la regulación actual del Patrimonio de la Seguridad Social.- $4^{\circ}$ Viabilidad del otorgamiento de concesiones administrativas sobre los bienes patrimoniales titularidad de la Tesorería General, a afectos a la prestación del servicio público sanitario en Andalucía: $4^{\circ} .1$. La afectación como elemento esencial de reconocimiento de la demanialidad.- $4^{\circ} .2$ Carácter instrumental del patrimonio público en la prestación de usos o servicios públicos.- 4º.3. Las concesiones administrativas como cobertura necesaria del uso privativo del dominio público o de bienes patrimoniales afectados a usos o servicios públicos.- $5^{\circ}$. Análisis patrimonial final. Inscripción registral y régimen jurídico de las obras, construcciones e instalaciones en concesiones administrativas.
\end{abstract}

I. RÉGIMEN JURÍDICO DE LOS BIENES DE LA SEGURIDAD SOCIAL TRASPASADOS A LA COMUNIDAD AUTÓNOMA DE ANDALUCÍA Y ADSCRITOS A LA PRESTACIÓN DEL SERVICIO PÚBLICO SANITARIO

\section{$1^{\text {o }}$ Régimen Jurídico del Patrimonio de la Seguridad Social}

Sin realizar un estudio exhaustivo de los antecedentes legislativos del mismo, baste señalar que el texto refundido de la Ley General de Seguridad Social aprobado por Decreto 2065/1974, de 30 de mayo (RCL 1974, 1482) configuró el patrimonio de la Seguridad Social como un patrimonio único, afecto a sus fines, distinto del Patrimonio del Estado. Posteriormente, y en el marco de la reforma y reorganización acometido en los primeros años de democracia, se 
asignó a la Tesorería General -una de las varias Entidades Gestoras creadasla titularidad, gestión y administración de este patrimonio ${ }^{1}$.

Este patrimonio se configuró desde el principio como excluido o al margen del dominio público del Estado. La doctrina administrativa no admitía en esos momentos por razones dogmáticas la existencia de bienes demaniales que no fueran de la titularidad de las Administraciones Públicas Territoriales, esto es, Estado y Entidades Locales en primera instancia, a las que se añadieron las Comunidades Autónomas tras el desarrollo del proceso autonómico. Por el contrario la denominada Administración Institucional o no territorial sólo podía ser titular de bienes patrimoniales, si bien podía tener adscritos bienes demaniales al objeto de utilizarlos estrictamente para los fines de la adscripción ${ }^{2}$, pero sin adquirir en ningún caso su propiedad. Esta fue la razón teórico-dogmática que determinó -como señala Ruiz-Jarabo Ferrán- la calificación de los bienes de la Seguridad Social como patrimoniales, el que las Entidades Gestoras de la Seguridad Social, -como Administración Institucional- no pudieran ser titulares o propietarias de dominio público porque esta titularidad estaba reservada a las Administraciones Públicas Territoriales. La diferencia y peculiaridad de este Patrimonio estribaría en que, -a diferencia del resto de la Administración Institucional a la que sólo se le permitía tener adscritos los bienes,- a las Entidades Gestoras se les terminó reconociendo la propiedad o titularidad dominical de estos bienes. Pero como señala acertadamente el autor citado, la precaria situación jurídica de estos bienes no tenía en esos momentos (1983) otra justificación que los enfoques cuasi-privatísticos o corporativistas de la etapa pre-

${ }^{1}$ El Real Decreto 255/1980, de 1 de febrero (RCL 1980, 335) atribuyó a la Tesorería General de la Seguridad Social la titularidad y administración del patrimonio único de la Seguridad Social y determina genéricamente las facultades de las distintas entidades respecto de los elementos integrantes de dicho patrimonio. Posteriormente, el Real Decreto 1314/1984, de 20 de junio (RCL 1984, 1819) asignó a la Tesorería General la titularidad, gestión y administración de los bienes y derechos que constituyen el patrimonio único de la Seguridad Social en la forma y condiciones que se establezcan por el Ministerio de Trabajo y Seguridad Social, sin perjuicio de las facultades atribuidas a las Entidades Gestoras de la Seguridad Social y a las Mutuas de Accidentes de Trabajo y Enfermedades Profesionales de la Seguridad Social.

${ }^{2}$ E. Ruiz-Jarabo Ferrán: "Patrimonio y Seguridad Social" RAP no 100-102. 1983 pág. 2.928 y ss; Las disposiciones del Código Civil (artículos 339 y 343) así como las Leyes de Entidades Estatales Autónomas (art. 10) y de Patrimonio del Estado (art. 12.3) conducen a excluir de la titularidad de los bienes demaniales a los entes públicos de carácter institucional, arbitrándose la figura de la adscripción (art. 80.2ํㅗ de la Ley Patrimonio del Estado) para solventar el problema de la permanencia de la propiedad en el ente territorial, mientras el uso pasa al institucional, por lo que queda inalterable la condición jurídica de los bienes objeto de la adscripción. Para estudio histórico ver pág. 2.933 y ss. 
cedente, que cada vez quedaban más inadecuados, a la vista de la expansión tanto subjetiva como objetiva, del propio Sistema de la Seguridad Social. ${ }^{3}$

En definitiva, los bienes de la Seguridad Social se han regulado -y regulan- como bienes patrimoniales. Y así, en efecto, el vigente Texto Refundido de la Ley General de Seguridad Social (aprobado por Real Decreto Legislativo 1/1994, de 20 de junio, artículos 80 a 85; LGSS en adelante) sigue regulándolos como un patrimonio único afecto a sus fines, distinto del Patrimonio del Estado.

La diferencia esencial entre el régimen jurídico de los bienes demaniales y los patrimoniales estriba en la inalienabilidad de los primeros ${ }^{4}$. Los bienes de dominio público son inalienables, inembargables e imprescriptibles y estos principios han sido constitucionalizados: el artículo 132.1 de la Constitución ha recogido dichas prerrogativas como principios esenciales de la demanialidad. ${ }^{5}$

Así pues, en principio este patrimonio de la Seguridad Social está sujeto al Derecho Privado -como el resto de los bienes en manos de particulares-, si bien que con un régimen de prerrogativas - menos intenso que en el dominio público- y de protección administrativa, en el que destaca la inembargabili-

${ }^{3}$ E. Ruiz Jarabo Ferrán, ibidem pág. 2.935: Pese a todo, no era obligado que la contratación (de obras, bienes, servicios y suministros) se ajustase a ninguna disposición especial, los contenciosos que de ella surgían se residenciaban en la jurisdicción civil, e, incluso, la relación existente entre el personal que prestaba servicios a las Entidades Gestoras y éstas, se estimaba de naturaleza laboral.

${ }^{4}$ M.F. Clavero Arévalo: "La inalienabilidad del dominio público" RAP no 25, 1958.

${ }^{5}$ La Sentencia 166/1998, de 15 de julio (Pleno) del Tribunal Constitucional señala que en atención a lo dispuesto en el art. 132.1 CE y en los arts. 338 a 345 del CCiv cabe apreciar, en efecto, que existen dos grandes categorías de bienes, los demaniales y los patrimoniales, cada una de ellas sometida a un régimen jurídico propio aunque exista una común intervención administrativa en orden a su gestión y protección. Y a los fines que aquí interesan es suficiente indicar que respecto de los bienes de dominio público y de los comunales el art. 132.1 CE ha establecido una protección reforzada al determinar que la inalienabilidad, imprescriptibilidad e inembargabilidad habrán de inspirar su regulación legal. Sin que este mandato constitucional, en cambio, se extienda a los bienes patrimoniales o de propios de las Entidades Locales, regidos por su legislación especifica y, en su defecto, por las normas de Derecho privado (art. 80.2 LBRL). El artículo 4 de la Ley 33/03 recoge este clasificación de forma pedagógica al señalar que por razón del régimen jurídico al que están sujetos, los bienes y derechos que integran el patrimonio de las Administraciones Públicas pueden ser de dominio público o demaniales y de dominio privado o demaniales. 
dad expresamente establecida en el artículo 85 LGSS y reiterada en la regulación reglamentaria del mismo, que inmediatamente analizamos. ${ }^{6}$

En efecto, la Disposición Adicional 3aㅡ de la Ley 33/2003, de 3 de noviembre, reguladora del Patrimonio de las Administraciones Públicas (LP en adelante; RCL 2003, 2594) prevé la aplicación sólo supletoria de ésta al Patrimonio de la Seguridad Social, salvo las normas sancionadoras de su Título IX, que serán de aplicación directa. En lo demás dicha Disposición remite a la legislación específica del Patrimonio de la Seguridad Social. Así pues, la regulación del régimen jurídico de dicho Patrimonio se encuentra en los artículos 80 a 85 de la vigente LGSS (citada anteriormente), desarrollados por el Real Decreto 1221/1992, de 9 de Octubre (RCL 1992\2410; BOE no 271, de 10 de Marzo; modificado parcialmente por Real Decreto 939/2001, de 2 de agosto-RCL 2001, 2293 y por el Real Decreto 1041/2005, de 5 de septiembre; RCL 2005, 1834).

\section{2º . Régimen Jurídico de los bienes inmuebles de la Seguridad Social transfe- ridos a la Comunidad Autónoma de Andalucía. Traspasos en materia sanitaria.}

Debemos acudir a la norma reguladora de los traspasos o, expresado con mejor precisión técnica, al correspondiente Acuerdo de la Comisión Mixta de Transferencias Estado-Comunidad Autónoma, conforme a lo previsto en la Disposición Transitoria $2^{a}$ del Estatuto de Autonomía para Andalucía (Ley Orgánica 6/1981, de 30 de diciembre).

El Acuerdo de la Comisión Mixta de Traspasos de las funciones, bienes y servicios del Instituto Nacional de la Salud (INSALUD en adelante) a la Comunidad Autónoma de Andalucía fue ratificado por Real Decreto 400/1984, de 22 de Febrero, (RCL 854,1984; BOE nº 51, de 29 de febrero; BOJA nº 24 de 13 de Marzo). ${ }^{7}$

\footnotetext{
${ }^{6}$ Así, los particulares pueden adquirir por usucapión bienes de la Seguridad Social, como expresamente admite el artículo 8 del Real Decreto 1221/1992, de 9 de Octubre. Esta posibilidad es inaceptable en los bienes demaniales y, como ya adelantamos desde ahora, respecto de este mismo patrimonio traspasado, afecto al servicio público sanitario y, por tanto, imprescriptible, en cuanto materialmente demanializado.

${ }^{7}$ Los Hospitales, Ambulatorios y Consultorios propiedad de la Seguridad Social figuran en el inventario detallado de la relación adjunta al citado Real Decreto como bienes inmuebles de ti-

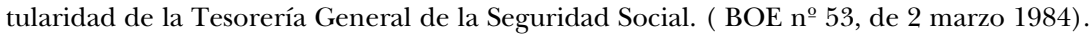


Los términos exactos del traspaso son los siguientes, conforme al Anexo I, apartado G del Acuerdo:

«G) Bienes, Derechos y obligaciones del Estado que se traspasan.

1. Se traspasan a la Junta de Andalucía los bienes, derechos y obligaciones del Instituto Nacional de la Salud que se recogen en el inventario detallado de la relación adjunta número 1. Estos traspasos se formalizarán de acuerdo con lo establecido en la disposición transitoria segunda del Estatuto de Autonomía de Andalucía y demás disposiciones en cada caso aplicables.

2. La adscripción de los bienes patrimoniales del Instituto Nacional de la Salud se entiende sin perjuicio de la unidad de patrimonio de la Seguridad Social, distinto del Estado y afecto al cumplimiento de sus fines específicos, cuya titularidad corresponde a la Tesorería General de la Seguridad Social.

El destino de los bienes de la Seguridad Social adscritos o que en el futuro se adscriban a la Junta de Andalucía para usos distintos de los actuales, siempre que los nuevos sean conformes a los fines propios de la Seguridad Social, se ajustará al procedimiento que por convenio se establezca, de acuerdo con la legislación básica del Estado.

3. En el plazo de un mes desde la aprobación de este Acuerdo por el Gobierno se firmarán las correspondientes actas de entrega y recepción de mobiliario, equipo y material inventariable.»

De la lectura atenta de este apartado G del Acuerdo Estado-Comunidad Autónoma de Andalucía se desprenden tres conclusiones:

$1^{\underline{a}}$ Los bienes del INSALUD afectos a la prestación de la asistencia sanitaria de la seguridad social han sido traspasados a la Junta de Andalucía, ordenando la norma de traspasos su formalización de conformidad con la D.T. $2^{\underline{a}}$ del Estatuto de Autonomía.

$2^{\underline{a}}$ El traspaso de este patrimonio no ha supuesto la pérdida de su titularidad dominical por parte de la Tesorería General de la Seguridad Social.

3 a Estos bienes han de estar destinados a los fines propios de la Seguridad Social. Es decir, a la prestación de la asistencia sanitaria de la Seguridad Social. ${ }^{8}$

\footnotetext{
${ }^{8}$ El Real Decreto-Ley 36/1978, de 16 de noviembre, creó el Instituto Nacional de la Salud (INSALUD) como la Entidad Gestora responsable de la gestión y administración de servicios sanitarios.
} 
Los cambios de destino de tales bienes habrán de ajustarse a un procedimiento conveniado entre la Comunidad Autónoma y el Estado, de acuerdo con la legislación básica del mismo.

En relación con esta tercera conclusión no debe perderse de vista cual fue y es el ámbito o sector de la acción administrativa al que se encontraban afectos estos bienes inmuebles de la Seguridad Social y cual es la distribución competencial que resulta del bloque de la constitucionalidad.

Muy sintéticamente señalaremos que, en primer lugar, el artículo 149.1.16 a de la Constitución Española sólo ha reservado al Estado competencia exclusiva sobre Sanidad exterior. Bases y coordinación general de la sanidad. Legislación sobre productos farmacéuticos. Por su parte, el artículo 148.1.21 de la Constitución permite que las Comunidades Autónomas puedan asumir competencias en materia de sanidad e higiene. Coherentemente con este diseño constitucional ${ }^{9}$ el Estatuto de Autonomía Andaluz asumió competencia exclusiva en materia de Sanidad e Higiene, sin perjuicio de lo que establece el artículo 149.1.16 de la Constitución.

La Ley 14/1986, de 25 de Abril, General de Sanidad (RCL 1986, 1316), norma básica dictada al amparo de la indicada reserva constitucional al Estado para establecer las bases y la coordinación general de la sanidad, crea el Sistema Nacional de Salud que se define como todas las estructuras y servicios públicos al servicio de la salud, y organizado en ese momento y en primera instancia como $\mathrm{el}$

\footnotetext{
${ }^{9}$ Es importante señalar que la Constitución Española de 1978 abordó de forma deliberada la separación de la materia sanitaria del ámbito de la Seguridad Social. El artículo 149.1.17 reservó al Estado la competencia exclusiva sobre Legislación básica y régimen económico de la Seguridad Social, sin perjuicio de la ejecución de sus servicios por las Comunidades Autónomas. Con esta separación del ámbito competencial se preparaba la futura transferencia a las Comunidades Autónomas de la gestión de la asistencia sanitaria pública, -en ese momento en gran medida a cargo del recientemente creado INSALUD como Entidad Gestora de la Seguridad Social-, pero también se daba soporte constitucional a la inmediata reforma sanitaria, proyectada desde mucho tiempo atrás, y que iba a determinar la unificación de los distintos y variados recursos públicos destinados a la misma y a su configuración como un verdadero servicio público sanitario y no ya sólo como una prestación más -aunque de gran importancia cuantitativa y cualitativa- en el elenco de prestaciones del Sistema de Seguridad Social. En este contexto de cambio -solo materializado parcialmente a partir de la Ley 14/1986, de 25 abril, General de Sanidad- es entendible la referencia en los Reales Decretos de transferencia de los servicios del INSALUD al País Vasco, Cataluña y Andalucía a la asistencia sanitaria de la seguridad socialy, por el contrario, difícilmente admisible en los Reales Decretos posteriores, pero sobre todo en la reciente transferencia de finales del 2001 a las CCAA que restaban por asumir competencias para la prestación del servicio público sanitario.
} 
conjunto de los Servicios de Salud de la Administración del Estado y de las Comunidades Autónomas, pero ya la Exposición de Motivos preveía la transferencia general de la gestión sanitaria a todas las CCAA al definir al Sistema Nacional de Salud como el conjunto de los Servicios de Salud de las Comunidades Autónomas convenientemente coordinados.

De acuerdo con la citada Ley básica del Estado, la Comunidad Autónoma de Andalucía creó el Servicio Andaluz de Salud, a virtud de la Ley Autonómica 5/1986, de 6 de mayo (BOE no 124, de 24 mayo; LAN 1986, 1406), cuyo artículo $1^{\circ}$ lo define como Organismo Autónomo de carácter administrativo de la Junta de Andalucía adscrito a la Consejería de Salud y Consumo... para la gestión y administración de los servicios públicos de salud. Su artículo $2^{\circ}$ asigna al Servicio Andaluz de Salud la gestión de los servicios y prestaciones de asistencia sanitaria de la Seguridad Social cuya gestión corresponda a la Junta de Andalucía y el artículo 16 b) le afecta los bienes y derechos de toda indole afectos a la gestión de los servicios sanitarios transferidos de la Seguridad Social.

Posteriormente la Ley 2/1998, de 15 de junio (LAN 1998, 241), de Salud de Andalucía, ha derogado en su mayor parte la Ley 8/86 pero mantiene la organización del SAS como Organismo Autónomo de carácter administrativo de la Junta de Andalucía adscrito a la Consejería de Salud y Consumo, encargado de la prestación de la asistencia sanitaria y la gestión y administración de los centros y los servicios sanitarios adscritos al mismo y que operen bajo su dependencia orgánica y funcional (artículos 64 y 65). ${ }^{10}$ Se mantiene así mismo en vigor el citado artículo 16 de la Ley 5/1986, que afecta al Servicio Andaluz de Salud el patrimonio transferido de la Seguridad Social.

La primera conclusión que cabe establecer, a la vista de la normativa expuesta, es que los centros sanitarios, titularidad de la Seguridad Social, y transferidos a virtud del Real Decreto 400/1984 a la Comunidad Autónoma de Andalucía, aunque inicial y formalmente son bienes patrimoniales materialmente están afectados a la prestación del servicio público sanitario: son bienes afectos al servicio público en sentido estricto. Existe una afectación/vin-

${ }^{10}$ La Ley Autonómica 2/98, de Salud, refuerza el carácter de servicio público sanitario al estructura el Sistema Sanitario Público de Andalucía, que define (art. 43) como el conjunto de recursos, medios organizativos y actuaciones de las Administraciones sanitarias públicas de la Comunidad Autónoma o vinculadas a las mismas, orientados a satisfacer el derecho a la protección de la salud a través de la promoción de la salud, prevención de las enfermedades y la atención sanitaria. 
culación directa de dichos bienes al destino público sanitario exigida por las propias normas del traspaso como elemento intrínseco de su mantenimiento o permanencia como bienes transferidos. Puede hablarse por ello de una afectación material, por tanto, preexistente a la transferencia y mantenida y reforzada tras ella, al dotarse la asistencia sanitaria de la seguridad social de todos los elementos definitorios y característicos del servicio público, y de una afectación también formal, establecida ésta por las propias normas del traspaso. Son las propias normas reguladoras del traspaso las que establecen la afectación de este patrimonio, tanto material como formal. La mutación se ha producido en el concepto asistencia sanitaria de la seguridad social que desde la promulgación de la Ley General de Sanidad se ha convertido en servicio público sanitario. Además, y como inmediatamente analizaremos, el Tribunal Constitucional y el Tribunal Supremo admiten la existencia de dicho concepto de afectación material, que exigen en todo caso para reconocer a los bienes patrimoniales la garantía de inembargabilidad y, en general, las prerrogativas reconocidas a los mismos en la legislación patrimonial, determinando esta Jurisprudencia una práctica equiparación en su régimen jurídico entre los bienes estrictamente demaniales y los patrimoniales afectos a usos o servicios públicos.

\section{3 - Referencia a los bienes inmuebles traspasados en la regulación actual del Patrimonio de la Seguridad Social.}

En primer lugar hemos de señalar que el artículo 2 del Real Decreto 1221/1992 limita el ámbito de aplicación de esta norma « a las Entidades Gestoras y Servicios Comunes de la Seguridad Social, así como a las Mutuas de Accidentes de Trabajo y Enfermedades Profesionales de la Seguridad Social, en las cuestiones que afecten a los bienes, derechos, acciones y demás recursos que integran el patrimonio único de la Seguridad Social."»

Pero, en particular, la disposición adicional sexta del Real Decreto 1221/92, se refiere específicamente a los bienes adscritos o que se adscriban en el futuro a las Comunidades Autónomas. Su cuya redacción literal es la siguiente:

\section{" Adscripción de bienes a las Comunidades Autónomas.}

1. Los bienes que integran al patrimonio único de la Seguridad Social que en el futuro hayan de adscribirse a alguna Comunidad Autónoma como consecuencia del traspaso de servicios, asi como el cambio de destino de los ya adscritos y la retrocesión de los 
mismos, en su caso, a la Seguridad Social, se ajustará al procedimiento establecido en el Acuerdo de traspaso.

2. Los bienes, derechos y demás recursos que integran el patrimonio único de la Seguridad Social que se hayan adscrito en virtud de un Real Decreto de traspaso a una Comunidad Autónoma, con anterioridad a la entrada en vigor del presente Real Decreto, se regirán por lo establecido en el correspondiente Acuerdo de la Comisión Mixta de Transferencias. Estos criterios serán de aplicación, asimismo, a las nuevas adscripciones y retrocesiones de los mismos."”

Por tanto la vigente regulación estatal confirma -como no podía ser menos, dados los términos del bloque de la constitucionalidad en materia de distribución de competencias y del traspaso de funciones y servicios- que el patrimonio adscrito a las Comunidades Autónomas se rige por las normas del traspaso. En el caso de Andalucía por el Acuerdo de la Comisión Mixta Estado-Comunidad Autónoma de Andalucía, elevado al Real Decreto 400/84, de 22 de febrero.

Esta conclusión confirma que los términos de la transferencia determinan la afectación indefinida de estos inmuebles a la prestación del servicio público sanitario en Andalucía (la antigua asistencia sanitaria de la seguridad social), siendo necesario para un cambio a otro servicio público no sanitario de aquéllos la celebración de un convenio con el Estado, que determinara los términos de tal mutación demanial. En caso de ser necesario o conveniente al interés público dejar de destinar estos inmuebles al servicio público sería necesario una desafectación. En los dos casos anteriores el destino de los bienes y los términos deben establecerse en convenio Estado-Comunidad Autónoma. Las facultades de la Comunidad Autónoma sobre este patrimonio transferido estarían vinculadas a su naturaleza de bienes afectos a la prestación de un servicio público,- el sanitario- servicio público de la competencia exclusiva autonómica. Su límite está en la titularidad dominical de la Tesorería General de la Seguridad Social, titularidad formal que asegura a futuro la unidad de este patrimonio afecto, -en todas las Comunidades Autónomas-, y su afectación a la prestación del servicio público sanitario.

$4^{\circ}$ Viabilidad del otorgamiento de concesiones administrativas sobre los bienes patrimoniales titularidad de la Tesorería General, a afectos a la prestación del servicio público sanitario en Andalucía.

$4^{\circ} .1$. La afectación como elemento esencial de reconocimiento de la demanialidad. 
La doctrina ha puesto de manifiesto la importancia de la afectación como elemento definitorio de la demanialidad ${ }^{11}$. Y puesto de relieve ${ }^{12}$ como la moderna categoría de los bienes de dominio público es heredera de la clasificación romana de las res extra commercium, y precisamente es la afectación como heredera de la publicatio romana la que confiere a los bienes públicos su característica extracomercialidad.

La Sentencia del Pleno del Tribunal Constitucional 166/1998, de 15 de julio ha ratificado la importancia de este elemento de la afectación, por encima de las simples categorías formales y la vigente Ley 33/2003, de 3 de noviembre, de Patrimonio de las Administraciones Públicas (LP), ha venido a confirmar plenamente la importancia de este elemento finalista. Su artículo 5 establece que son bienes de dominio público los que, siendo de titularidad pública, se encuentren afectados al uso general o al servicio público, y sitúa en segundo lugar la demanialización por ley -así como aquellos a los que una ley otorgue expresamente el carácter de demaniales. Además su artículo 66, después de establecer como norma general la afectación por acto expreso añade que surtirá los mismos efectos que la afectación expresa... la utilización pública, notoria y continuada por la Administración General del Estado o sus organismos públicos de bienes y derechos de su titularidad para un servicio público o para un uso general. En coherencia con la admisión de un concepto de afectación material junto a la regla general de la afectación for-

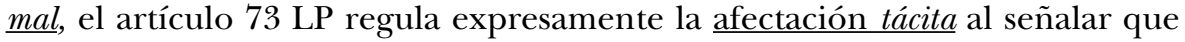
los bienes y derechos patrimoniales de la Administración General del Estado podrán ser adscritos a los organismos públicos o dependientes de aquélla para su vinculación directa a un servicio de su competencia, o para el cumplimiento de sus fines propios. En ambos casos, la adscripción (el subrayado es nuestro) llevará implícita la afectación del bien o derecho, que pasará a integrarse en el dominio público.

${ }^{11}$ L. Parejo Alfonso: "Dominio Público: un ensayo de reconstrucción de su teoría general". RAP n⿳o 100-102, 1983; pág. 2.418, apartado IV "La afectación como pieza clave del dominio público". En su nota 55 da cuenta de la doctrina mayoritaria: La afectación es una figura central (E. García de Enterría), medular (F. Garrido Falla) o, en todo caso, básica (Villar Palasí, M. Clavero). El autor remite a M. Sánchez Blanco: "La afectación de bienes al dominio público" Instituto García Oviedo 1979).

M.F. Clavero Arévalo: "La inalienabilidad del dominio público" RAP no 25, 1958. Puede considerarse como doctrina dominante la de los autores que piensan que el régimen jurídico administrativo del dominio público tiene por base la idea de afectación... el régimen del dominio público encuentra su fundamento en la afectación; pág. 36 y ss.

${ }^{12}$ Santiago Castán Pérez-Gómez: "De la romana institución de la publicatio a la actual noción de afectación”. REDA nº 96, Octubre-Diciembre 1997. 
Es claro, por tanto, que la entrada en la demanialidad de los bienes patrimoniales viene determinada tanto por un expediente de afectación expresa como por una afectación material o afectación en sentido propio, que, precisamente responde al concepto expresado en la citada Sentencia de Pleno del Tribunal Constitucional 166/1998, de 15 de Julio (RTC 1998\166). ${ }^{13}$

La prevalencia de este elemento teleológico o finalista sobre el meramente formalista de la existencia de expediente de afectación expresa está confirmado por el propio artículo 73 LP. Después de señalar en el apartado 2 que los bienes de un organismo público podrán ser adscritos al cumplimiento de fines propios de otro, el apartado 3 termina declarando que la adscripción no alterará la titularidad sobre el bien. Este declaración tiene gran trascendencia para el objeto del presente estudio porque confirma la prevalencia del elemento finalista sobre el puramente formal y la plena compatibilidad de la titularidad patrimonial de una Administración Pública -y en particular la del Estadocon la adscripción a otra para su afectación a un servicio público. Es precisamente el supuesto en el que se encuentra el patrimonio de la seguridad social afecto a la prestación del servicio público sanitario, tanto en Andalucía como en el resto de Comunidades Autónomas. Los Acuerdos de las Comisiones Mixtas Estado-CCAA de traspasos de los bienes de la Seguridad Social que tenía adscritos el INSALUD (y los Reales Decretos a que han sido elevados) son precisamente los instrumentos de afectación o vinculación expresa de este patrimonio al destino público sanitario, porque todos ellos han retenido precisamente la titularidad en poder de la Tesorería General, retención que entendemos como instrumento o garantía de la indicada afectación a futuro.

A análogas conclusiones lleva el estudio de la Ley 4/1986, de 5 de mayo, de Patrimonio de la Comunidad Autónoma de Andalucía (LAN 1986\1393). $\mathrm{Su}$ artículo 3.b comienza por incluir expresamente como de dominio público o demaniales aquellos bienes y derechos que sean transferidos a la Comunidad Autónoma y se afecten a un uso o servicio público. El artículo 46 principia la regulación del Capítulo III de la Ley, -centrada en la afectación y desafectación de los

13 STC 166/1998, FJ 11. De este modo, se ha sostenido que las Administraciones Públicas han de contar con bienes de distinta naturaleza para el cumplimiento de sus diversas funciones. Y se ha puesto de relieve, además, que la distinción se relativiza no sólo por la aparición de importantes patrimonios separados del Patrimonio del Estado y al servicio de concretos fines, sino también por la flexibilización - en la práctica y pese a las exigencias legales- de la desafectación de un bien demanial de un uso o servicio público, lo que permite a la Administración recuperar su disponibilidad como objeto de tráfico privado. Registrándose también, a la inversa, el fenómeno de la afectación material de bienes de naturaleza patrimonial a finalidades de interés general. 
bienes demaniales-, con la declaración de que la afectación es el acto por el cual un bien o derecho perteneciente a la Comunidad Autónoma de Andalucía o Entidad dependiente de ella es destinado a un uso o servicio público. A continuación el artículo 48 sistematiza adecuadamente las formas de la afectación señalando que podrá tener lugar por a) por Ley b) por silencio y c) mediante acto expreso o tácito. Por su parte, el artículo 57 como claro precedente del citado artículo 73 de la LP dispone que Podrán cederse bienes muebles o inmuebles de forma gratuita u onerosa a Entidades públicas para uso o servicio público de competencia de ellas. El bien patrimonial cedido quedará así afecto a un uso o servicio público ajeno al cedente, pasando a ser de dominio público sin que suponga cambio de titularidad.

Finalmente, más expresivo aún -y adelantado en el tiempo a las formulaciones indicadas- es el artículo 4.2 del Reglamento para la Aplicación de la Ley del Patrimonio de la Comunidad Autónoma de Andalucía (Decreto 276/1987, de 11 de noviembre; BOJA no 2, de 8 enero 1988) al establecer que son bienes de servicio público aquellos afectos a actividades públicas en sentido amplio que, en el campo de sus competencias, correspondan a la Comunidad Autónoma de Andalucía o a las Entidades de Derecho Público de ella dependientes, aunque el servicio no sea explotado directamente por una u otras.

Precisamente, este precepto reglamentario termina poniendo de manifiesto la prevalencia del elemento finalista de la afectación sobre la circunstancia -dependiente de criterios de oportunidad o financieros- de que el servicio público se preste de forma directa por la Administración o bien -indirectamente- por medio de concesionarios.

\section{$4^{\circ}$.2. Carácter instrumental del patrimonio público en la prestación de usos o servicios públicos.}

Debemos comenzar -por su importancia- por la ya citada Sentencia del Tribunal Constitucional 166/1998 que sitúa la esencia de la demanialidad -y por tanto de su inembargabilidad que fue el objeto directo de la cuestión de inconstitucionalidad resuelta por la Sentencia- en la afectación al uso o servicio público, afectación que cabe establecer respecto de los bienes patrimoniales, en cuyo caso gozarán también del privilegio de la inembargabilidad:

«FJ 12. Como antes se ha dicho, cuando un bien se halla materialmente afectado a un servicio público o a una función pública específica, constituye el «soporte material» de dicha actividad (STC 227/1988, fundamento jurídico 14) y, por tanto, es un medio material necesario para la realización efectiva de los intereses generales a los que sirve la Administración. De suerte que su inembargabilidad está justificada en 
atención a la eficacia de la actuación de la Administración Pública y la continuidad en la prestación de los servicios públicos. Mientras que no cabe estimar otro tanto respecto a los bienes patrimoniales de una Entidad local no afectados materialmente a un servicio público o una función pública, pues el interés general sólo está presente en atención a su titular, un ente público, pero no en cuanto a la actuación que a aquélla corresponde llevar a cabo ni al ejercicio de concretas potestades administrativas.» En el mismo sentido el Tribunal Supremo -Sala de lo Contencioso Administrativo- en su Sentencia de 19 de diciembre de 2001 (RJ 2002, 9946; FJ 4º).

Esta instrumentalidad del demanio respecto del servicio público está expresamente reconocida en nuestro ordenamiento jurídico administrativo. El artículo $87 \mathrm{LP}$ establece que la utilización de los bienes y derechos destinados a la prestación de un servicio público se supeditará a lo dispuesto en las normas reguladoras del mismo y, subsidiariamente, se regirá por esta Ley. El artículo $91 \mathrm{LP}$, al regular las autorizaciones y concesiones demaniales, añade que no será necesario obtener estas autorizaciones o concesiones cuando el contrato administrativo habilite para la ocupación de los bienes de dominio público.

Es la misma regulación que ya se venía estableciendo en la legislación de Régimen Local ${ }^{14}$. El artículo 74 del Reglamento de Bienes de las Entidades Locales (Real Decreto 1372/1986, de 13 de junio) dispone con mucha claridad que no necesita de ulterior comentario que: 1. La utilización de los bienes de dominio y uso público se regirá por las disposiciones de esta sección. 2. El uso de los bienes de servicio público se regirá, ante todo, por las normas del Reglamento de Servicios de las Entidades Locales y subsidiariamente por las del presente. 3. Las normas del Reglamento de Servicios serán asimismo de preferente aplicación cuando la utilización de bienes de uso público fuere sólo la base necesaria para la prestación de un servicio público municipal o provincial.

Finalmente la Ley de Patrimonio de la Comunidad Autónoma de Andalucía sí se refiere -en un intento de sistematizarlas- a las modalidades de concesiones administrativas existentes en dicho momento, pero se remite, en definitiva, al referirse a las concesiones de obras y de servicios públicos a la legislación especial y de contratación administrativa, y viene igualmente a establecer el mismo régimen de subsidiaridad de la legislación patrimonial respecto de aquélla, al disponer su artículo 33 que:

\footnotetext{
${ }^{14}$ Como pone de relieve E. Colom Piazuelo: "La gestión de los servicios públicos por las Administraciones Locales y el dominio público: posibilidades de articulación” REDA no 101 Enero-Marzo 1999.
} 
b)... Cuando para la prestación de ese servicio público sea necesario el uso común especial de un bien de dominio público perteneciente a la Comunidad Autónoma, la autorización para ese uso se entenderá implícita en la concesión del servicio. También se entenderá implícitamente otorgada la concesión para uso privativo de aquellos bienes de dominio público pertenecientes a la Comunidad Autónoma necesarios para la prestación del servicio público... c)... Cuando la obra necesite ocupar bienes de dominio público de la Comunidad Autónoma de Andalucía, la autorización o concesión, en su caso, se entenderá implícita en la concesión de obras y servicios.

\section{4. .3 . Las concesiones administrativas como cobertura necesaria del uso privativo del dominio público o de bienes patrimoniales afectados a usos o servicios públicos.}

La Ley de Patrimonio Andaluza y la Ley Estatal 33/03 de Patrimonio de las Administraciones Públicas (LP) no divergen prácticamente a la hora de regular la utilización de los bienes y derechos, tanto de los destinados al uso general como al uso o servicio público. Comienza estableciendo la Ley Andaluza que el uso de los bienes de dominio público podrá ser común o privativo. Aquél, a su vez, general o especial. Uso común es aquél que corresponde por igual a todas las personas, sin que la utilización por parte de unas impida la de otras... Uso privativo es el que origina una ocupación de bien intensa y tendente a permanecer, de forma que se impida su libre uso a otras personas. El artículo 32 de la Ley de Patrimonio Andaluza ordena que Todo uso privativo, sea en favor de personas públicas o privadas, exige previa concesión administrativa. Este artículo 32 de la Ley Andaluza es coincidente con el 86.3 de la LP al decir ésta que el uso privativo de los bienes de dominio público que determine su ocupación con obras o instalaciones fijas deberá estar amparado por la correspondiente concesión administrativa.

Volviendo a los términos jurídicos exactos del traspaso a Andalucía, examinados anteriormente, concluimos que la Comunidad Autónoma tiene competencia exclusiva para la prestación del servicio público sanitario, respecto del que, el patrimonio de la Seguridad Social transferido es el soporte material -y no exclusivo hoy día- necesario para su efectiva prestación, en los términos expresados por la STC 166/1998, por lo que existe una manifiesta afectación material de dicho patrimonio a la prestación de un servicio público de los calificados como esenciales. Las normas de traspaso confieren a la Comunidad Autónoma el uso de tal patrimonio transferido sin más limitación que $1^{\circ}$ el respeto de la titularidad dominical de la Tesorería General y $2^{\circ}$ el mantenimiento de la afectación a la prestación de la asistencia sanitaria. El uso de este patrimonio -como en general de todo el patrimonio público materialmente 
afectado a usos o servicios públicos - tiene carácter instrumental del propio servicio público, al que se encuentra vinculado ${ }^{15}$, teniendo la legislación patrimonial carácter subsidiario respecto de la legislación reguladora de dicho servicio público, normativa ésta por la que se rige su uso o utilización. Así pues la Comunidad Autónoma -en la prestación del servicio público sanitario- puede utilizar tanto la gestión directa como cualquiera de los instrumentos normativos específicamente previstos para las formas de gestión indirecta, entre las cuales destaca la concesión administrativa, tanto en su acepción clásica como modalidad strictu sensu del contrato de gestión de servicios públicos como en las restantes modalidades de la misma reguladas en la vigente legislación básica de contratación administrativa, también conectadas a la satisfacción del servicio público, aunque no constituyan estrictamente objeto de aquélla modalidad contractual, pero utilizables cuando concurran los requisitos exigidos legalmente, como es el caso de la concesión de obras públicas, regulada ahora como nuevo contrato administrativo típico en el Título V del Libro II de la Ley de Contratos de las Administraciones Públicas (Real Decreto Legislativo 2/2000, de 16 de junio; RCL 2002\1380), añadido por la Ley 13/2003, de 23 de mayo (RCL 2003\1373), así como la concesión demanial, como forma específica de retribución del contrato administrativo de obras, incorporada como nueva modalidad de éste por la Ley 13/03. En todos estos casos la concesión da cobertura legal al uso privativo de este patrimonio por un contratista, directamente vinculado dicho uso a la satisfacción de un interés público, teniendo por tanto y, en resumen, título jurídico habilitante la Comunidad Autónoma de Andalucía para el otorgamiento de concesiones administrativas sobre el patrimonio traspasado de la Seguridad Social.

Como ya ha quedado también expuesto anteriormente, el Servicio Andaluz de Salud es el Organismo Autónomo de carácter administrativo que tiene adscrito desde su creación por la Ley Autonómica 5/1986, de 6 de mayo (cuyo artículo 16 se mantiene en vigor expresamente por la Ley 2/1998, de Salud de Andalucía) este patrimonio transferido de la Seguridad Social, por lo que, siendo así mismo la Administración Institucional encargada de la prestación del servicio público sanitario en nuestro ámbito territorial, es el competente para -en aplicación de la legislación de contratación administrativa y en ejecución de la misma- la adjudicación de los pertinentes contratos administra-

15 L. Parejo Alfonso: "Dominio Público: un ensayo de reconstrucción de su teoría general". RAP no 100-102, 1983; pág. 2418 y ss. El autor analiza el concepto de vinculación a un destino público como caracterización moderna del dominio público, por encima de la heterogeneidad de regulaciones existentes en el patrimonio de las Administraciones Públicas. 
tivos que comporten el otorgamiento de concesiones sobre dicho patrimonio, de ser necesario o conveniente para la correcta prestación del servicio público en los Centros e Instituciones Sanitarias adscritas.

\section{$5^{\circ}$. Análisis patrimonial final. Inscripción registral de las concesiones adminis- trativas y régimen jurídico de las obras, construcciones e instalaciones.}

Finalmente, analizamos las implicaciones estrictamente patrimoniales de las conclusiones anteriores, por su importancia a la hora de conseguir la imprescindible seguridad jurídica que requiere la obtención de financiación pública o privada para la ejecución de nuevas infraestructuras afectadas o vinculadas a la prestación del servicio público sanitario, pero también la adecuada defensa de los intereses generales en la gestión del patrimonio afecto a dicho servicio público.

Es ya un clásico en la doctrina administrativa española la existencia de un fenómeno evidente -ya casi secular- de huida del Derecho Administrativo en la gestión diversa de las Administraciones Públicas, así como de una privatización o desregulación de actividades antes en la órbita del sector público. ${ }^{16}$ En lo que nos afecta en este análisis, es público y notorio el fenómeno reciente -a influjo británico- de la ejecución de grandes infraestructuras públicas con financiación privada mediante instrumentos jurídicos que determinan en muchos casos su titularidad, también privada ${ }^{17}$. Las fórmulas jurídicas empleadas hasta ahora han sido variopintas ${ }^{18}$ y muy vinculadas o caracterizadas por la necesidad de las garantías exigidas por los proveedores de dicha financiación privada, entre las que destacan las inmobiliarias así como por las exigencias de seguridad jurídica. La promulgación de la Ley 13/2003, reguladora del Contrato de Concesión de Obras Públicas, está - precisamente- vinculada de forma directa a la necesidad de las Administraciones Públicas Españolas para la ob-

${ }^{16}$ Elisa Moreu Carbonell: «Desmitificación, privatización y globalización de los bienes públicos: del dominio público a las «obligaciones de derecho público" RAP no 161 Mayo-agosto 2003

\footnotetext{
17 Son múltiples y diferentes las fórmulas de colaboración privada en la construcción y mantenimiento de infraestructuras públicas, e incluso en la prestación de servicios públicos. Se denominan en inglés "public-private partnerships" (PPP, esta es la denominación que utiliza Eurostat) o "private finance initiative (PFI), término que prevalece en el mundo anglosajón; así en la web del Tesoro de su Majestad Británica.

${ }^{18}$ Fernando Azofra Vega: "La financiación privada de infraestructuras públicas"; REDA nº 96 Octubre-Diciembre de 1997.
} 
tención de colaboración de la iniciativa privada para la financiación de dichas infraestructuras públicas, al regular numerosas y variadas formas de retribución del concesionario de obras públicas. ${ }^{19}$

Esta Ley 13/2003 supone -entre otras muchas cosas- una clara apuesta por la seguridad jurídica en la contratación administrativa de las infraestructuras, en el aspecto de la regulación -incorporada al Capítulo IV del Título Vde las indicadas fórmulas de financiación privada (resumidamente, la hipoteca de la concesión y la titulización de los derechos de crédito del concesionario). Para ello requiere inexcusablemente la inscripción de la concesión en el Registro de la Propiedad (artículos 254ํ‥1, 255‥1 y 258 Ley de Contratos de las Administraciones Públicas, LCAP en adelante). Esto no es extraño en absoluto en el Ordenamiento Jurídico Español porque ya el artículo $334.10^{\circ}$ del Código Civil incluía -e incluye- en la categoría de bienes inmuebles a las concesiones administrativas de obras públicas y las servidumbres y demás derechos reales sobre bienes inmuebles. Y, por su parte, la vigente Ley Hipotecaria define en su artículo 107.․ 6 . como hipotecables a las concesiones administrativas... de obras destinadas al servicio público, regulando detalladamente su inscripción en el Registro de la Propiedad el Reglamento Hipotecario (artículos 60 y ss). A este respecto, debemos señalar que la regulación positiva civil-inmobiliaria de la concesión administrativa la configura como un bien inmueble asimilado o derecho real inscribible que, por ello mismo, tiene acceso al Registro de la Propiedad, conforme a una doctrina sólida y reiterada de la Dirección General de los Registros y el Notariado, a la que inmediatamente hacemos referencia.

En efecto muy importante es, a los efectos que estudiamos, la Resolución de la Dirección General de los Registros y el Notariado de 16 de julio 2002 (RJ 2002, 9317). Esta Resolución estimó el recurso gubernativo interpuesto por los concesionarios contra la calificación de la Registradora de la Propiedad que denegó la inscripción en el Registro de una concesión administrativa sobre el edificio "Palacio de Godoy", por no ser dominio público sino bien patrimonial del Ayuntamiento de Aranjuez. La Dirección General, con la practicidad mencionada, estima el recurso y anula la denegación de la Registrado$\mathrm{ra}$, estableciendo que nuestro sistema registral establece el sistema de «numerus apertus» para la constitución de derechos reales (cfr. artículo 2.2 de la Ley Hipotecaria),

${ }^{19}$ Ariño Ortiz, Gaspar y Villar Escurra, José Luis "Reflexiones sobre el proyecto de reforma de las concesiones de obra", Revista de Obras Públicas $n^{\circ} 3425$ (2002) Es probable que las novedades de mayor calado en toda la reforma vengan de la mano de los numerosos sistemas de retribución del concesionario y que admiten todas las modalidades imaginables tanto privadas como públicas y, sobre todo, mixtas. 
siendo inscribibles los derechos que son reales aunque no sean tipicos o nominados y, además, otros que no son tales, como el arrendamiento (cfr. artículo 2.6 de la misma Ley), por lo que el único problema que plantea la escritura presentada es si lo que se constituye en la escritura presentada es un derecho inscribible. La Registradora entiende que no puede constituirse una concesión sobre bienes patrimoniales, pero, sin necesidad de entrar en tal cuestión, es lo cierto que se constituye a favor de la "concesionaria» un derecho al uso exclusivo del bien cedido, durante cincuenta y cinco años, a cambio de determinadas obligaciones y del pago de un canon anual. Es obvio, por tanto, que, independientemente del nombre que se dé al derecho concedido (concesión, derecho de superficie, derecho de arrendamiento, etc.), lo cual es irrelevante (pues lo esencial es el contenido del mismo), o, aunque no se le dé ninguno, el derecho configurado tiene todas las características que permiten su inscripción, pues, o bien se le considera como un derecho real, o bien como uno de arrendamiento, no siendo relevante la denominación que las partes den al contrato si los derechos y obligaciones de ambas están correctamente establecidos.

Así pues, e insistiendo en la demanialidad por afectación material del patrimonio de la Seguridad Social transferido a la prestación del servicio público sanitario no existen, por otro lado obstáculos formales al otorgamiento de concesiones administrativas sobre el mismo, pese a su carácter de bienes $p a$ trimoniales, aunque ello sea en una concepción meramente formalista que ya hemos desechado anteriormente. Pero desde el punto de vista del pragmatismo inherente a los elementos de la seguridad jurídica-característico y definitorio de la doctrina de la Dirección General de los Registros y el Notariadono existe impedimento teórico para el acceso de tal clase de concesiones administrativas al Registro de la Propiedad, lo que refuerza por otro lado, la solidez jurídica en la aplicación señalada de la Ley $13 / 03 .^{20}$

Por tanto, a la vista de la regulación normativa en su conjunto -jurídico privada y jurídico pública- es indudable la naturaleza jurídica de la concesión administrativa como derecho realy, como tal, accesible al Registro de la Propiedad. El supuesto normal, obviamente, será el de la construcción de infraestructuras -obras destinadas al servicio público, como dice la Ley Hipotecaria-, por lo que junto a la propia concesión como derecho real inscribible surgirán obras, construcciones $e$ instalaciones, con su propia entidad inmobiliaria, que es preci-

${ }^{20}$ Entendemos, en definitiva, que es la propia concesión la que ha de determinar la apertura de un folio registral autónomo sin que sea, por ello, requisito necesario el otorgamiento de escrituras públicas de declaración de obra nueva del artículo 208 de la Ley Hipotecaria y 308 del Reglamento Hipotecario, como vehículo intermedio para permitir el acceso de las concesiones administrativas al Registro de la Propiedad. 
samente lo que pretendemos clarificar en este último apartado. Por otro lado, es importante poner de manifiesto que también cabe la posibilidad de concesiones que no implican la construcción de tales obras e instalaciones, como es el caso de las concesiones de obra pública cuyo objeto se limita a la explotación y el mantenimiento de las infraestructuras, expresamente admitidas por el artículo 220 LCAP, aunque el Consejo de Estado discrepara con esta ampliación del concepto concesional. ${ }^{21}$

Es importante, por ello, determinar con claridad el régimen jurídico aplicable a esas obras, construcciones e instalaciones: las infraestructuras públicas cuya consecución se ha revelado estratégica y que, en definitiva, persiguen todas las Administraciones Públicas Españolas.

Para su regulación hay que atender en primer lugar a los artículos 97 y 98 de la Ley 33/03, de Patrimonio de las Administraciones Públicas (LP), que tienen el carácter de normas básicas. El artículo 97 establece que: 1. El titular de una concesión dispone de un derecho real sobre las obras, construcciones e instalaciones fijas que haya construido para el ejercicio de la actividad autorizada por el título de la concesión. 2 Este título otorga a su titular, durante el plazo de validez de la concesión y dentro de los límites establecidos en la presente sección de esta Ley, los derechos y obligaciones del propietario. Los subrayados son nuestros. El artículo 98 añade que los derechos sobre las obras, construcciones e instalaciones de carácter inmobiliario a que se refiere el artículo precedente sólo podrán ser cedidos o transmitidos mediante negocios jurídicos entre vivos o por causa de muerte o mediante la fusión, absorción o escisión de sociedades, por el plazo de duración de la concesión, a personas que cuenten con la previa conformidad de la autoridad competente para otorgar la concesión. Análoga regulación, aunque no tan explícita, resulta de los artículos 7 y 28 de la Ley de Patrimonio Andaluza al declarar que las obras ejecutadas por los concesionarios o los bienes que éstos destinen al cumplimiento de la concesión continuarán siendo de su propiedad hasta su entrega a la Administración por causa de rescate, reversión, caducidad

${ }^{21}$ El Dictamen del Consejo de Estado sobre el Anteproyecto de Ley de Concesión de Obra Pública discrepó con esta ampliación del objeto del contrato a sólo la explotación de una obra pública, por considerar que desfigura el concepto esencial de la concesión: En otros términos, el Anteproyecto opta por ampliar notablemente la noción de concesión de obras públicas, refiriéndola no solamente a los casos en que tiene por objeto la "construcción y explotación" de la obra pública, sino también a aquellos en que tiene por objeto únicamente la "explotación" de la obra ya construida (...). debe llamarse la atención sobre el hecho de que la generalización de tal previsión, inspirada claramente en la legislación sectorial de autopistas, unido a otras prevenciones del Anteproyecto como las referidas a las ayudas de la Administración en la ejecución de la obra (artículo 22.1 y 2) y las excepciones al principio de riesgo y ventura por causa de fuerza mayor (artículo 24.2. y 3), desvirtúa en buena medida los perfiles legales que definen la institución concesional. 
o por cualquier otro motivo. Añadiendo el 28 la facultad de la Administración para ejercer sus potestades públicas de recuperación, investigación y deslinde para la defensa de los bienes que no sean de su titularidad... afectos a una concesión administrativa.

En rigor, la regulación anterior se refiere a las concesiones demaniales y debe entenderse como el reconocimiento de derechos reales limitados supeditados, ante todo, a la terminación del derecho concesional y sujetos en su posible transmisión a la previa autorización administrativa. Es claro, por ello, que el reconocimiento de estos derechos reales sobre las obras, construcciones e instalaciones en el dominio público deben entenderse de forma muy restrictiva, habida cuenta el principio general -constitucionalizado- de inalienabilidad del dominio público, principio igualmente desarrollado en la legislación patrimonial.

No obstante, debemos analizar el alcance preciso de dicha regulación. Como señalamos con anterioridad la legislación patrimonial estatal, autonó-

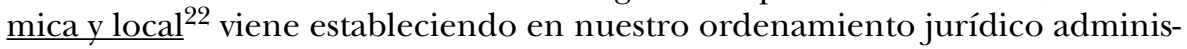
trativo el principio de la subsidiaridad de la misma respecto de los bienes afectos a usos o servicios públicos, que se rigen por la legislación reguladora del respectivo servicio público y, lógicamente, respecto de la normativa de contratación administrativa.

El propio estudio detenido de la reciente legislación estatal confirma la subsidiaridad tradicional. Así el artículo 98 LP en su párrafo segundo, -y de forma paralela a la Ley 13/03- admite como uno más de los derechos reales a constituir sobre las obras, construcciones e instalaciones la hipoteca de los $d e$ rechos sobre los mismos así como la titulización de los derechos de cobro de los créditos garantizados con dicha garantía hipotecaria (art. 99 LP). Llamamos la atención de que la hipoteca que regula la Ley 13/03 y la garantía inmobiliaria de la titulización de los derechos de crédito del concesionario no son las obras, construcciones e instalaciones sino la concesión misma. Es la concesión de obras públicas, como derecho real inscribible en el Registro de la Propiedad la garantía inmobiliaria de los negocios jurídico-privados necesarios para proveer de financiación privada la construcción de las infraestructuras públicas. La di-

${ }^{22}$ Artículo 87 de la Ley 33/2003, de 3 de noviembre, de Patrimonio de las Administraciones Públicas; artículo 74 Reglamento de Bienes de las Entidades Locales (Real Decreto 1372/1986, de 13 de junio); art.33 Ley 4/1986, de 5 de mayo, de Patrimonio de la Comunidad Autónoma de Andalucía. 
ferencia es considerable, por tanto: mientras que la legislación patrimonial admite la hipoteca sobre las propias obras, construcciones e instalaciones en el ámbito de la contratación administrativa es la propia concesión el derecho real hipotecable. Ello es así porque, no debe olvidarse que las obras, construcciones e instalaciones objeto de las concesiones de obras y de servicios son, o bien el propio objeto perseguido por la acción pública -infraestructuras de todo tipo- o bien elementos instrumentales en la prestación de usos o servicios públicos, conforme al concepto de afectación-vinculación teleológica que es la clave, elemento esencial, medular o básico del dominio público. Por ello carece de sentido la admisión de la constitución de derechos reales limitados sobre las propias infraestructuras públicas y, además, es innecesario toda vez que la configuración normativa de la concesión como derecho real-definitivamente clarificado su régimen jurídico por la Ley 13/03- permite con la mayor seguridad jurídica la obtención de financiación privada. Sólo así se comprende cabalmente la regulación contenida en el artículo $101 \mathrm{LP}$, esto es que el destino de las obras, construcciones e instalaciones al finalizar la concesión demanial sea la demolición, salvo que se cedan gratuitamente y libres de cargas y gravámenes a la Administración.

En todo caso y como ya hemos señalado, rigiendo el principio de subsidiaridad de la aplicación de la legislación patrimonial bastará con que los pliegos de cláusulas administrativas particulares reguladores de los contratos de concesión administrativa- de obras / servicios públicos- excluyan la posibilidad de adquisición de tales derechos reales limitados sobre las obras, construcciones e instalaciones, habida cuenta de que tales infraestructuras van a estar afectas a la prestación del servicio público sanitario, compadeciéndose mal ello con el reconocimiento de derechos reales, además innecesarios desde el momento en el que la propia Ley de Contratos de las Administraciones Públicas regula con todo detenimiento y seguridad jurídica los mecanismos de financiación privada que tienen a los propios rendimientos económicos de la concesión como garantía real inmobiliaria. Esta solución nos parece respetuosa y coherente con la perspectiva jurídico-pública que ha de presidir la acción administrativa en materia de contratación pública y, al mismo tiempo, más operativa y beneficiosa para los intereses generales que las visiones estrictamente iusprivatisticas, que pueden dar lugar a un tráfico jurídico privado -legal- pero innecesario para la consecución de infraestructuras públicas.

Es por tanto este punto uno de los elementos clave en los que la Ley 13/03 ha venido a proporcionar la seguridad jurídica que precisa el acometimiento de ambiciosos proyectos de generación de infraestructuras, porque ha venido a clarificar de un lado el régimen jurídico aplicable -habida cuenta el 
necesario acceso al Registro de la Propiedad de las concesiones de obras públicas per se-, sin necesidad de establecer alambicadas fórmulas jurídicas, y de otro lado, ha establecido una regulación jurídico pública disciplinadora del control administrativo de estas fórmulas de financiación privada -necesidad de autorización administrativa previa, control de la solvencia económica y financiera de los posibles adquirentes de las concesiones, etc-. Singular relevancia tiene a estos efectos el artículo 260 LCAP, que viene a suponer un nuevo avance en la tradicional teoría de los actos separables al atribuir al Orden Jurisdiccional Civil las cuestiones litigiosas derivadas de las fórmulas jurídico-privadas de financiación privada, sin perjuicio, claro está, de la competencia de la Jurisdicción Contencioso Administrativa para el enjuiciamiento de las indicadas potestades administrativas conferidas por la Ley 13/03 sobre dichos negocios jurídico privados instrumentales para la obtención de financiación privada.

La clarificación del régimen jurídico de la concesión la entendemos absolutamente indispensable a la vista del claro proceso de privatización de infraestructuras y del patrimonio público que estamos contemplando en el último decenio. Significativa a este respecto es la Sentencia del Tribunal Supremo -Sala de lo Contencioso Administrativo- de 6 de mayo de 1999 (RJ 1999/4300). El Alto Tribunal ratificó la anulación de un concurso público para la construcción de aparcamientos subterráneos y galerías comerciales en el subsuelo, en régimen de concesión demanial con un plazo de 99 años por entender el Ayuntamiento de Avilés que la explotación de aparcamientos en el subsuelo era una mera actividad económica. El Tribunal Supremo se pronunció a favor por un concepto amplio y no restrictivo del servicio público, que no requiere que una Ley reserve expresamente un sector de actividad a la Administración, calificando dicha actividad de aparcamiento público como servicio público municipal en régimen de concesión, por su clara conexión con otras competencias municipales, como la ordenación del tráfico de vehículos.

Por otro lado, la Dirección General de los Registros y el Notariado, como ya hemos expuesto anteriormente, ha marcado una pauta muy clara en la vigencia del sistema de numerus apertus en la configuración de los derechos reales y su accesibilidad al Registro de la Propiedad, y ello tiene particular relevancia respecto de los bienes públicos, abordados desde la óptica iusprivatísti$c a$. Muy ilustrativa, es a este respecto la Resolución de 5 de abril de 2002 (RJ 2002\8121). El Pleno del Ayuntamiento de Oviedo decidió la desafectación de parte del subsuelo del "Parque de Invierno", parte conocida como "Palacio de los Niños", con la finalidad de la construcción de un aparcamiento subterráneo de dos plantas. El Ayuntamiento acordó su inclusión en el Inventario Mu- 
nicipal de Bienes como folio registral autónomo independiente como bien patrimonial, absolutamente diferenciado de la finca superior que le sirve de soporte, que constituye el Parque de Invierno y que continúa siendo bien de dominio público. Asimismo se acuerda la inscripción en el Registro de la Propiedad del subsuelo desafectado, como finca independiente. El Registrador de la Propiedad denegó la inscripción por considerar que la nueva finca registral recaía sobre un volumen que al estar absolutamente diferenciado de la finca superior que le sirve de soporte... absolutamente desconectado de la superficie terrestre, no puede constituirse como finca independiente, para ser objeto jurídico susceptible de dominio... contraviniendo ello normas imperativas reguladoras del derecho de propiedad, en cuanto a su extensión y accesión. La Dirección General estimó el recurso gubernativo interpuesto por el Ayuntamiento de Oviedo contra la calificación del Registrador, admitiendo la inscripción del complejo inmobiliario. Además de una extensa argumentación sobre el contenido actual del derecho de propiedad ${ }^{23}$, lo decisivo es la admisión del acceso al Registro de formas nuevas: En nuestro Derecho inmobiliario registral rige un principio de "numerus apertus» en la configuración de los derechos reales (cfr. artículos 2 Ley Hipotecaria y 7 de su Reglamento), de manera que siempre que se respeten las exigencias impuestas a favor de terceros por el sistema registral existe pleno respeto al principio de autonomía de la voluntad y a la libertad en la creación de nuevas figuras jurídico-reales. Por ello, la Dirección General constata que la jurisprudencia ha admitido la posibilidad de un uso privativo del subsuelo, sin que por ello se perjudique el carácter demanial del suelo y... en nada queda mermado el destino público del suelo por el hecho de que el subsuelo sea objeto de aprovechamiento privativo.

${ }^{23}$ F.D ${ }^{\circ} 2^{\circ}$ : Lo cierto es que el principio de accesión del dominio (artículo 363 del Código Civil) tiene excepciones, que pueden tener su origen en la voluntad del propietario (caso de la constitución de un derecho real de superficie, de un derecho real de vuelo o de subedificación) o en la propia Ley... No cabe interpretar los preceptos del Código Civil relativos a la propiedad y a la accesión, según el viejo aforismo romano «usque ad sidera usque ad infero". Esta concepción liberal del dominio se ha visto extensamente modulada por la legislación especial y no se corresponde a la actual configuración del derecho de propiedad en nuestra Constitución. El dominio no se configura como un derecho ilimitado y unitario, en el que sólo por vía de ley cabe restricciones a su contenido sino que por el contrario la función social de la propiedad delimita intrinsecamente su extensión (cfr. artículo 33 de la Constitución). El aforismo «usque ad sidera usque ad infero» referido a los derechos del propietario, cede frente al superior principio de la función social de la propiedad, de manera que además de las leyes especiales limitativas deben tenerse en cuenta aquellas otras cuyo objeto es la delimitación de las facultades del propietario, como ocurre en materia urbanística (cfr. artículo 2 de la Ley del Suelo [RCL 1976, 1192; ApNDL 13889]).Las normas urbanísticas pueden permitir asi un uso diverso para el subsuelo distinto del correspondiente al suelo. Para ello será premisa indispensable, que tal posibilidad no sea contradictoria con el planeamiento, y que si los terrenos inicialmente eran dotacionales públicos se cumplan los requisitos legales en orden a la desafectación como bien demanial del subsuelo para su configuración como bien patrimonial. 
En definitiva la Dirección General de los Registros y el Notariado ha venido a posicionarse en una clara perspectiva pragmática y no dogmática, conforme a la cual los marcos registrales no deben coartar las soluciones exigidas por las necesidades de las relaciones económicas, siempre que se respeten las normas fundamentales que estructuran el régimen inmobiliario.

En este punto hemos volver sobre nuestras posiciones anteriores. Hemos concluido sobre la procedencia del otorgamiento de concesiones administrativas sobre el patrimonio de la seguridad social transferido a la Comunidad Autónoma y afecto al Servicio Andaluz de Salud para la prestación del servicio público sanitario, pero entendemos -en una perspectiva estrictamente jurídico-pública- que las concesiones administrativas instrumentales de usos y servicios públicos han de tener acceso al Registro de la Propiedad como derecho real per se, sin necesidad de reconocer específicos derechos reales sobre las obras, infraestructuras o instalaciones objeto de dichas concesiones, lo que, a la vista del pragmatismo de la Dirección General de los Registros y el Notariado y la dicción literal de los artículos 97 a 99 de la Ley 33/03 de Patrimonio Estatal, podría llegar a verificarse.

Por último, nos limitaremos a una observación respecto de la -todavía reciente- transferencia sanitaria, y que lógicamente está fuera de nuestro análisis, al ser las normas de traspaso diferenciadas, aunque todas ellas con una redacción prácticamente idéntica en lo que respecta al traspaso del patrimonio de la Seguridad Social que tenía adscrito el INSALUD para la prestación asistencia sanitaria pública en dichas CCAA. En efecto, los Reales Decretos 1471, 1472, 1473, 1474, 1475, 1476, 1477, 1478, 1479, 1480/2001, respectivamente, todos de fecha 27 diciembre 2001 (RCL 2001, 3255, 3202, 3203, 3230, 3204, 3205, 3231, 3206, 3207 y 3208), sobre traspaso a las Comunidades Autónomas de Asturias, Cantabria, La Rioja, Murcia, Aragón, Castilla La Mancha, Extremadura, Illes Balears, Madrid y Castilla y León, de las funciones y servicios del Instituto Nacional de la Salud, dedican una redacción idéntica a esta mate$\mathrm{ria}^{24}$. Nos choca que se haya transferido este patrimonio como estrictamente

\footnotetext{
${ }^{24}$ El texto es el siguiente: Se adscriben a la Comunidad Autónoma de... los bienes patrimoniales afectados al Instituto Nacional de la Salud que se recogen en el inventario detallado de la relación adjunta número 3.Esta adscripción se entiende sin perjuicio de la unidad del patrimonio de la Seguridad Social, distinto del del Estado y afecto al cumplimiento de sus fines específicos, cuya titularidad corresponde a la Tesorería General de la Seguridad Social, debiendo figurar los inmuebles adscritos en el Balance de la Seguridad Social, en la forma que determine la Intervención General de la Seguridad Social.8. La Comunidad Autónoma disfrutará el uso de los bienes inmuebles de la Seguridad Social que se adscriben, debiendo hacerse cargo de todas las reparaciones necesarias en orden a su conservación, efectuar las obras de mejora que estime convenientes,
} 
patrimonial lo que entendemos indefendible habida cuenta el evidente carácter de servicio público de la asistencia sanitaria pública, desgajada ya en el momento de la transferencia -incluso presupuestariamente- del sistema de Seguridad Social. Lógicamente, al haberse abordado la transferencia en el entendimiento de tratarse de bienes patrimoniales sujetos al Derecho Privado los conceptos utilizados en los Acuerdos-RRDD de transferencias son eminentemente iusprivatistas con todas las disfunciones que ello puede determinar en el futuro en la gestión de los servicios públicos sanitarios en dichas CCAA.

Para concluir, es interesante hacer referencia al artículo 183 LP que, con el carácter de norma básica, se refiere expresamente al principio de lealtad institucional, como inspirador de las relaciones recíprocas de las Administraciones Públicas en materia patrimonial, principio que ordena a éstas facilitarse la información necesaria, cooperación y respeto a las respectivas competencias, llamando en última instancia a la ponderación en el ejercicio de las mismas de la totalidad de los intereses públicos implicados.

ejercitar las acciones posesorias que, en defensa de los mismos, procedan en Derecho, así como subrogarse en el cumplimiento de las obligaciones tributarias que afecten a dichos inmuebles a partir de la fecha de efectividad del traspaso.9. Los bienes inmuebles del patrimonio de la Seguridad Social adscritos revertirán, conforme a lo dispuesto en las normas reguladoras del patrimonio de la misma a la Tesorería General en el caso de no uso o cambio de destino para el que se adscriben, debiendo continuar la Comunidad Autónoma con el abono de los gastos derivados de su conservación y mantenimiento, así como del pago de las obligaciones tributarias que afecten a los mismos, hasta la finalización del ejercicio económico en el que se produzca dicho cambio o falta de uso.11. Los bienes inmuebles sitos en el territorio de la Comunidad Autónoma de... que hayan sido cedidos a la Tesorería General de la Seguridad Social para la construcción de Centros Sanitarios, en los que no se haya iniciado la ejecución del contrato de obras, conforme al artículo 142 del texto refundido de la Ley de Contratos de las Administraciones Públicas, aprobado por Real Decreto Legislativo 2/2000, de 16 de junio, revertirán al cedente.12. Las obras de nueva edificación, asi como las de ampliación que supongan modificación de la estructura externa sobre inmuebles o terrenos transferidos, realizadas por la Comunidad Autónoma de... se integrarán definitivamente en el Patrimonio de la misma, con respeto, en todo caso, de los derechos de suelo y vuelo de la Tesorería General de la Seguridad Social, sin perjuicio de que se arbitren de mutuo acuerdo las medidas oportunas para que, conforme a la legislación civil, hipotecaria y administrativa vigentes, se hagan efectivas tales finalidades, pudiendo instrumentarse, a tal efecto, la celebración de convenios entre ambas Administraciones. 